\title{
Dental Stimulation to the Buccal Mucous Membrane Causes Lumbago: A Report of Two Cases
}

\author{
Yoshiro Fujii \\ Shin Kobe Dental Clinic, Kobe, Japan \\ Email: shin-kobe-dentalclinic@s9.dion.ne.jp
}

Received 18 July 2015; accepted 22 August 2015; published 25 August 2015

Copyright (C) 2015 by author and Scientific Research Publishing Inc.

This work is licensed under the Creative Commons Attribution International License (CC BY). http://creativecommons.org/licenses/by/4.0/

(c) (i) Open Access

\begin{abstract}
This study aims to demonstrate that harmful stimulation of the buccal mucosa because of a rough tooth surface may cause lumbago. This report illustrates two cases of women in their $30 \mathrm{~s}$ and $40 \mathrm{~s}$ who are suffering from lumbago due to unknown causes. The patients are cured by a simple dental procedure in which the buccal surface of a molar is smoothened, thereby inhibiting the negative stimulation of the buccal mucosa. Soon after this treatment, the symptoms of lumbago have subsided. The reason for the effectiveness of this treatment remains unclear. However, the balance dysregulation observed in the patient may have been due to stimulation of the oral mucous membrane by the rough surface of the tooth. It is important for dentists to pay attention to the effects of tooth formation, dental restorations, and dental prosthetics on the entire body. A dental condition may have an effect on diseases affecting other parts of the body; thus a dental treatment may be considered as an option for the management of other systemic disorders. It appears that cooperation between the fields of dentistry and medicine is of utmost importance.
\end{abstract}

\section{Keywords}

Oral Mucous Membrane, Balance Dysregulation, Tooth Formation, Lumbago

\section{Introduction}

Studies have shown that the oral conditions, especially occlusion, are closely associated with other parts of the body, e.g. body posture, temporomandibular disorder, cervicobrachial issues [1]-[4]. In addition, the author has reported the relationship between electromagnetic waves and systemic conditions affecting the body [5]-[11] However, to the author's knowledge, the relationship between tooth form and systemic disorders has not been 
reported so far. This study presents two subjects with lumbago, caused as a result of harmful dental stimulation of the oral mucous membrane, whose symptoms are cured by altering the buccal surface of a tooth.

\section{Case Reports}

\subsection{Case 1: Subject and Method}

The subject was a woman in her 30s who had been suffering from lumbago, particularly in the vicinity of L4-L5 (L: Lumbar region) for almost 10 years. She felt pain when she leaned backwards, and was unable to bend forward and touch the floor with her fingers. The distance between the floor and her fingertips was approximately 5 cm (Figure 1).

The Bi-Digital O-ring Test (BDORT) [12] [13] was used to test for grasping power, which was found to be decreased (O-ring open) when the subject leaned backwards (Figure 2). Her O-ring was also opened when the center of her back was stimulated by a chopstick (Figure 3). Furthermore, the application of pressure on the subject's cheek in the vicinity of the left lower second molar, resulted in a decreased grasping power, so her O-ring opened (Figure 4).

The sharp buccal surface of the left lower second molar was considered to be harmfully stimulating the buccal

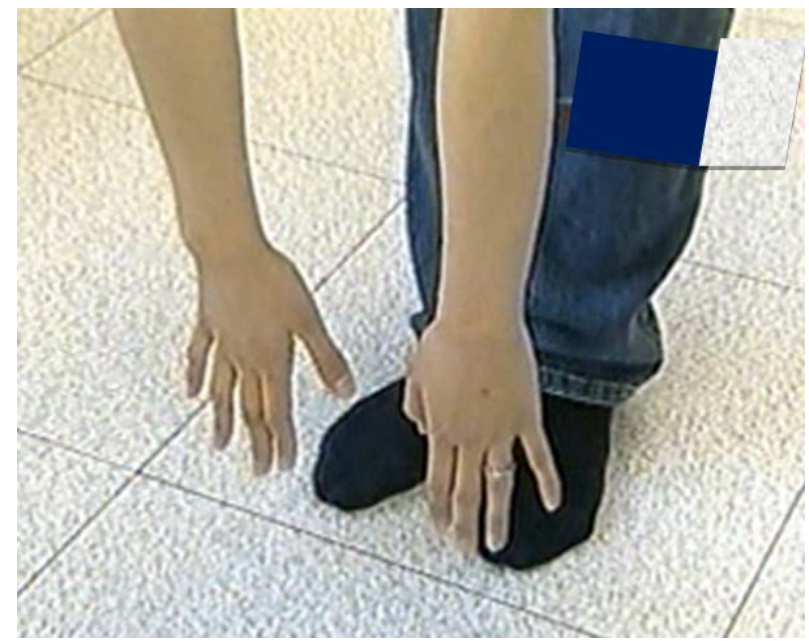

Figure 1. The subject could not bend forward and touch the floor with her fingers. The distance between the floor and her fingertips was approximately $5 \mathrm{~cm}$.

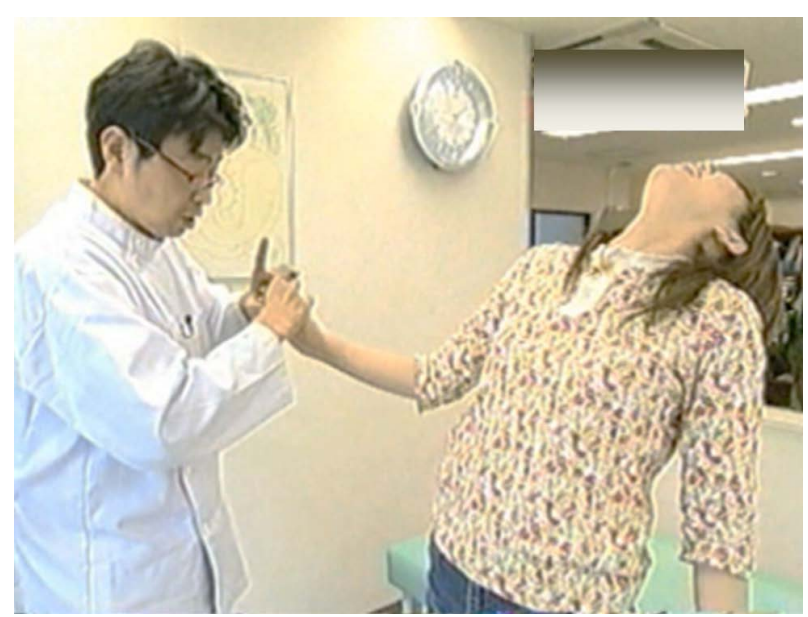

Figure 2. The subject presented with a decrease in grasping power while leaning backwards. So, her O-ring opened. 


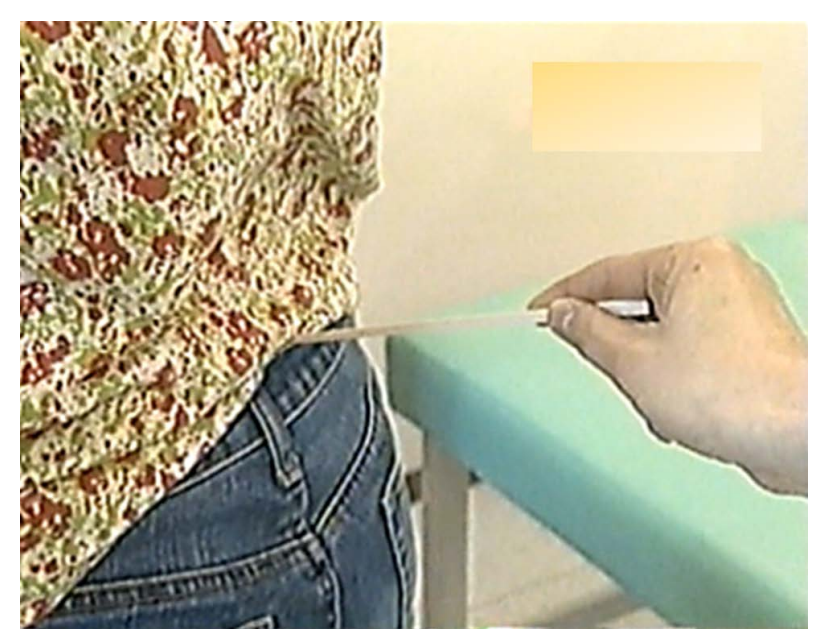

Figure 3. The subject's grasping power was also decreased when the center of her back was stimulated by a chopstick.

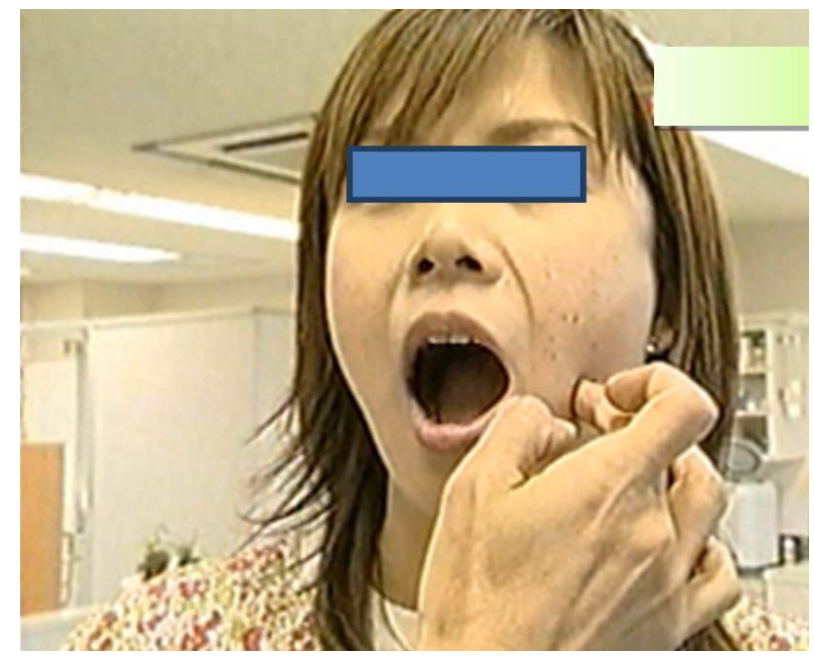

Figure 4. Touching the subject's cheek surface over the left lower second molar led to a decrease in grasping power.

membrane: thus it was smoothened (Figure 5, Figure 6). Soon after this simple procedure, the subject was able to touch the floor with her fingertips with ease (Figure 7), and no longer felt pain when she leaned backwards. When performing BDORT, her grasping power did not decrease (O-ring closed) when she leaned backwards or when the center of her back was stimulated by a chopstick. The effectiveness of this treatment continued for over a year.

In order to watch the actual experiment described in this case please visit YouTube movie.

Holistic dentistry vol.1_3 2'10" 6'33".

https://www.youtube.com/watch?v=vySULOcPrTE (last accessed 08/11/2015).

\subsection{Case 2: Subject and Method}

The subject was a housewife in her 40s, who had been suffering from lumbago for several years. She felt pain while bending her body backwards (Figure 8). When the SLR (Straight Leg Raising) test was performed on her right leg, the subject felt tension and pain. The subject's right leg was lifted up to an angle of approximately 80 degrees (Figure 9). She also complained of tension and pain when her right knee was abducted (Figure 10).

The subject was gently pushed while keeping her mouth opened, resulting in her falling down (Figure 11). Similarly, a gentle push of the lower part of her upper cheek area easily destabilized the subject (Figure 12). 


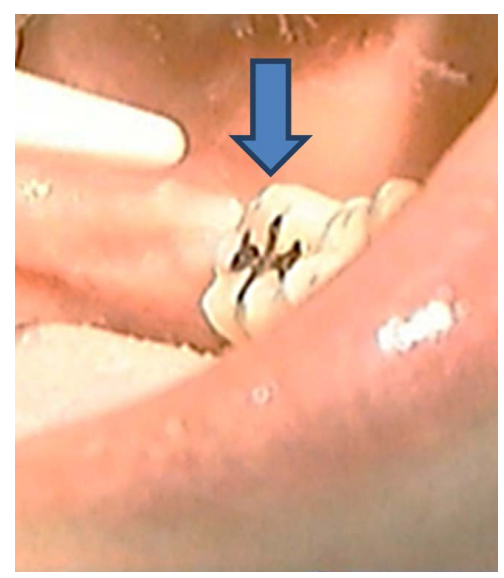

Figure 5. A sharp edge located on the buccal surface (arrow) of the left lower second molar was considered to be causing lumbago in the subject.

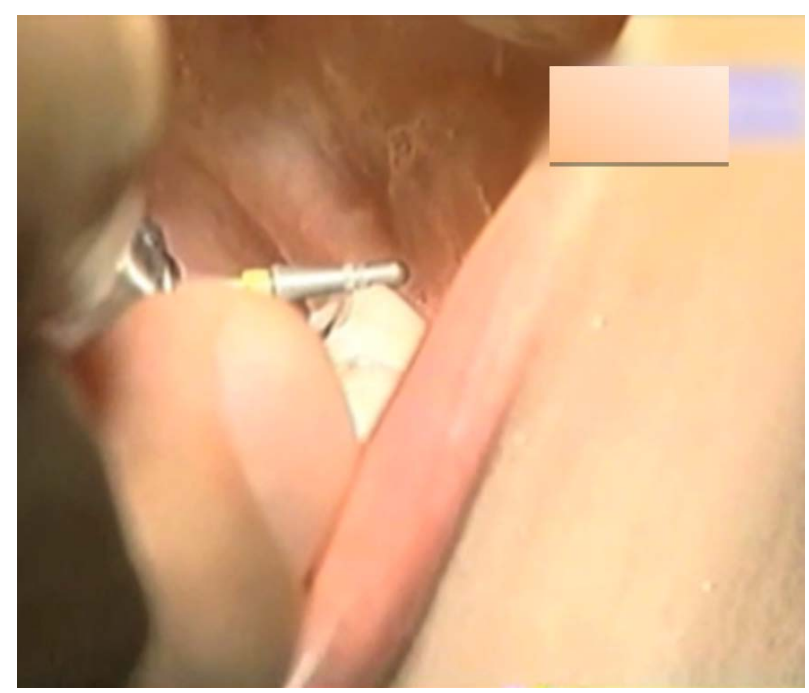

Figure 6. Smoothening of the sharp edge on the buccal surface of the lower left molar.

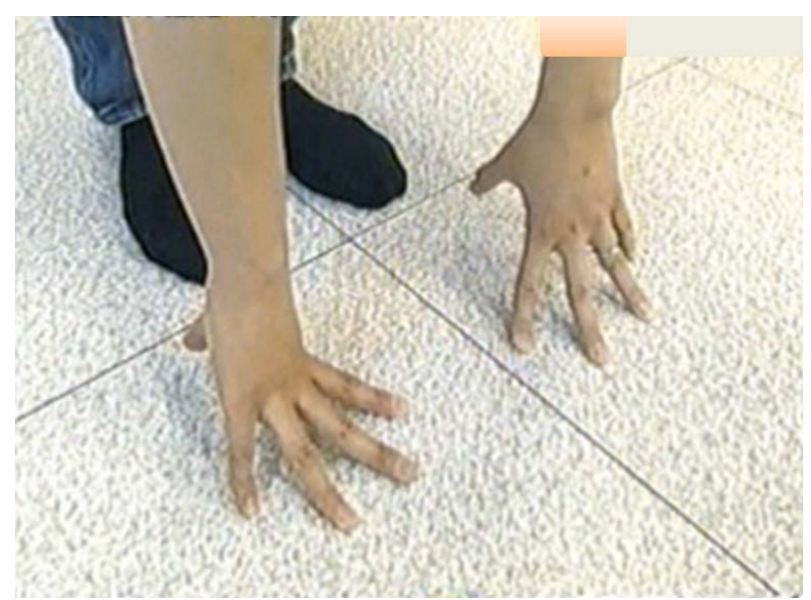

Figure 7. Soon after this simple treatment, the subject could easily bend forward and touch the floor with her fingertips. 


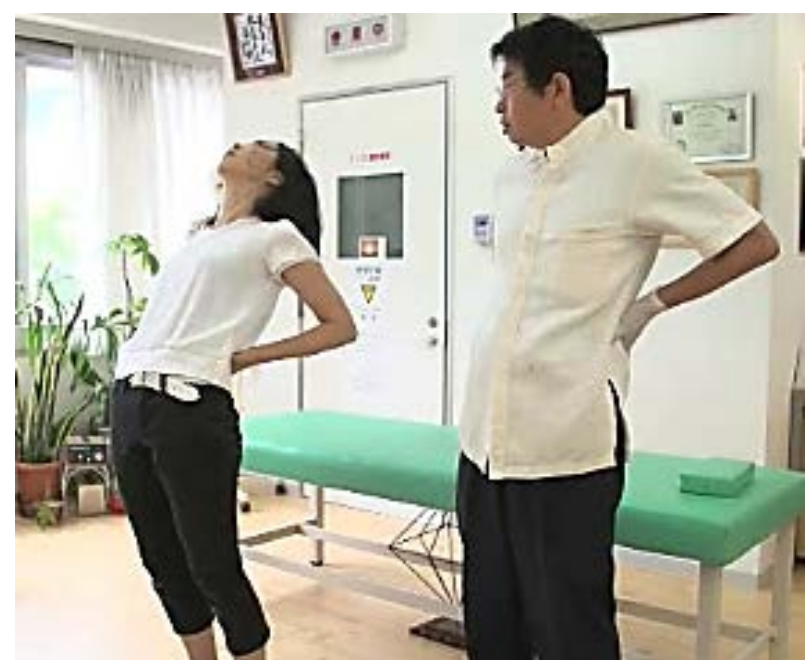

Figure 8. The subject felt pain when she leaned backwards.

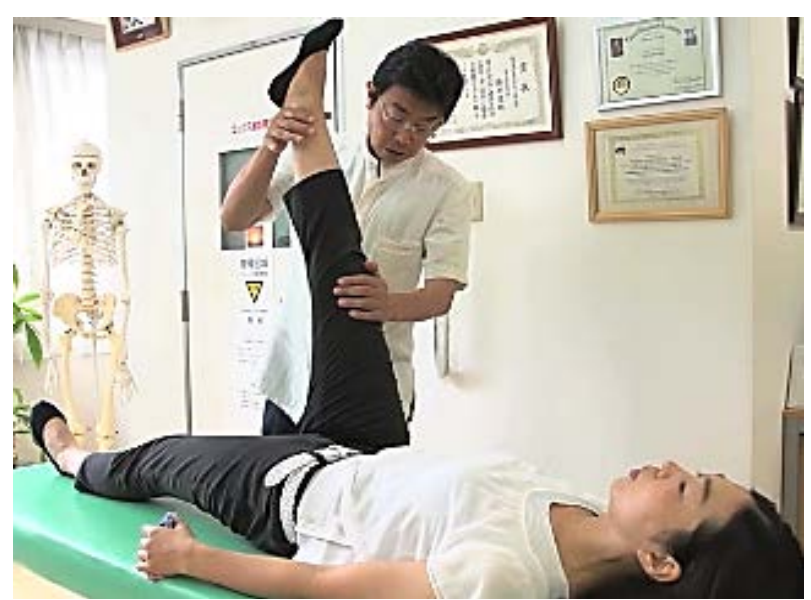

Figure 9. The subject felt tension and pain when her right leg was lifted to an angle of approximately 80 degrees during the SLR (Straight Leg Raising) test.

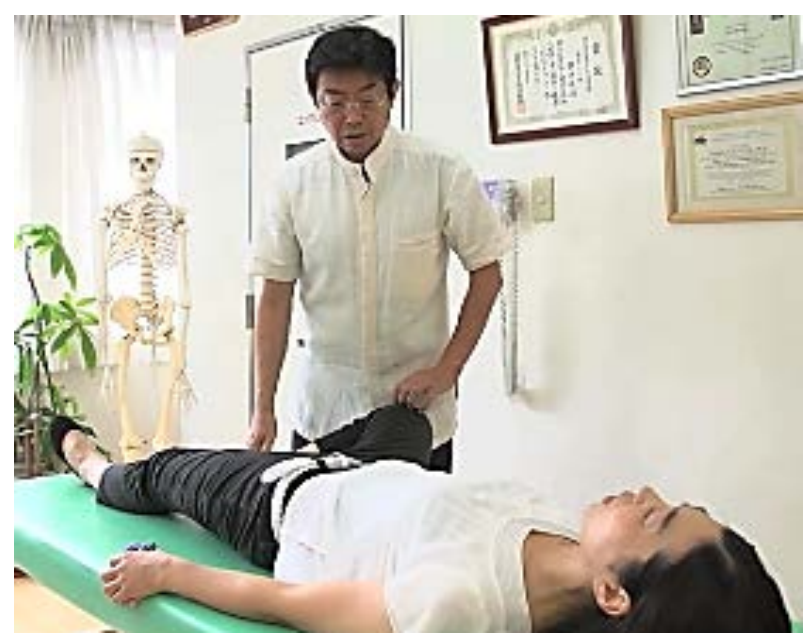

Figure 10. The subject complained tension and pain when her right knee was abducted. 


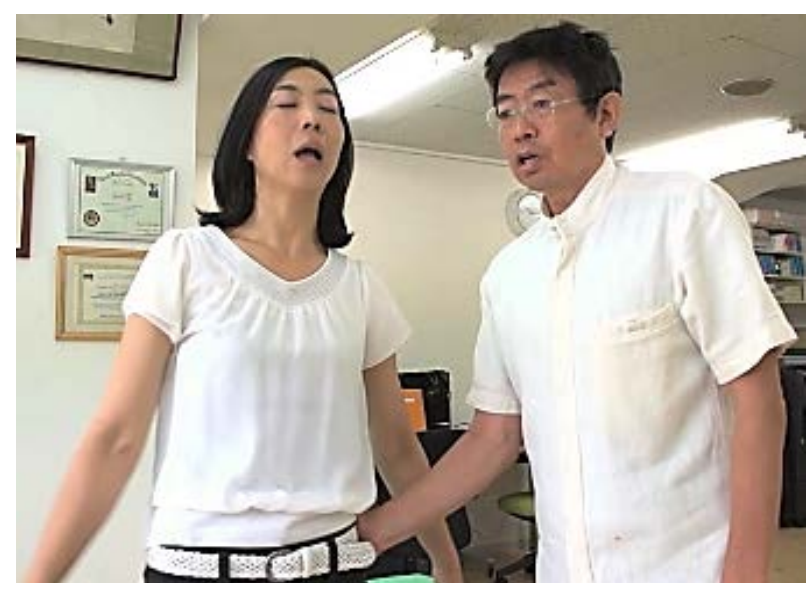

Figure 11. The subject was easily destabilized while keeping her mouth opened when the author pushed her body.

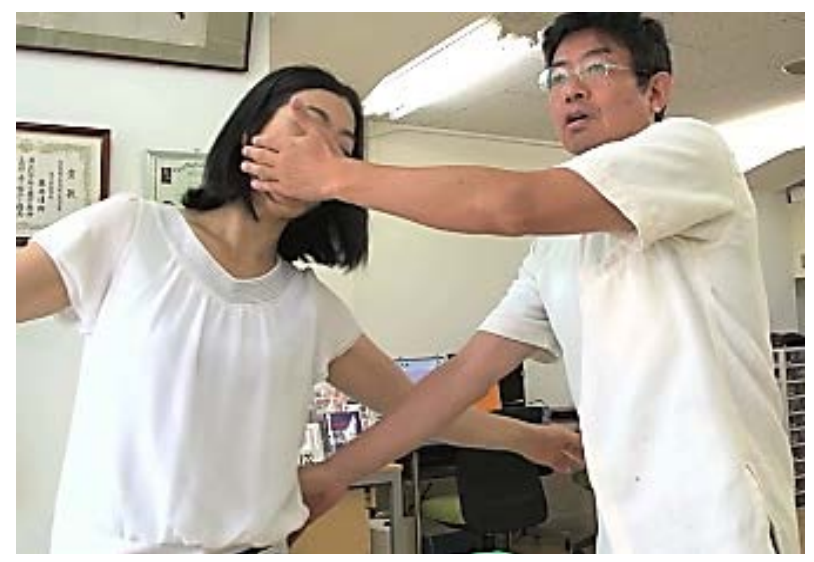

Figure 12. The subject was easily destabilized while the lower portion of her upper cheek was pushed.

Moreover, the subject was easily destabilized when the author inserted his finger into the subject's mouth between the right lower second molar and the buccal mucosa.

The sharp edge on the buccal surface of right lower second molar was considered to be the cause of her symptom: this was smoothened as described in Case 1 . Soon after this simple procedure, the subject could no longer be destabilized when being pushed while keeping her mouth opened. She did not complain of any pain when the right SLR test was performed: the subject's right leg was able to be lifted up to an angle of approximately 90 degrees (Figure 13). No pain was felt while abducting the right knee or while leaning backwards. There was no recurrence of symptoms after a follow-up period of one month.

In order to watch the actual experiment described in this case please visit YouTube movie.

A tooth stimulation to buccal mucous membrane caused body balance dysregulation.

https://www.youtube.com/watch?v=xitZdprCL7Y (last accessed 06/23/2015).

\section{Discussion}

Some reports have demonstrated the relationship between occlusion and body posture, temporomandibular disorders, and cervicobrachial conditions [1]-[4]. However, associations between tooth imperfection and lumbago have not been reported so far. In the present study, two subjects with lumbago were treated by correcting the buccal surface of the molar. In Case 1, the left lower second molar appears to have stimulated the buccal mucosa, resulting in opening of the O-ring and leading to lumbago. Similarly, in Case 2, the stimulation of the buccal mucosa by the subject's right lower molar appears to have caused a dysregulation in balance. In this case, the subject presented 


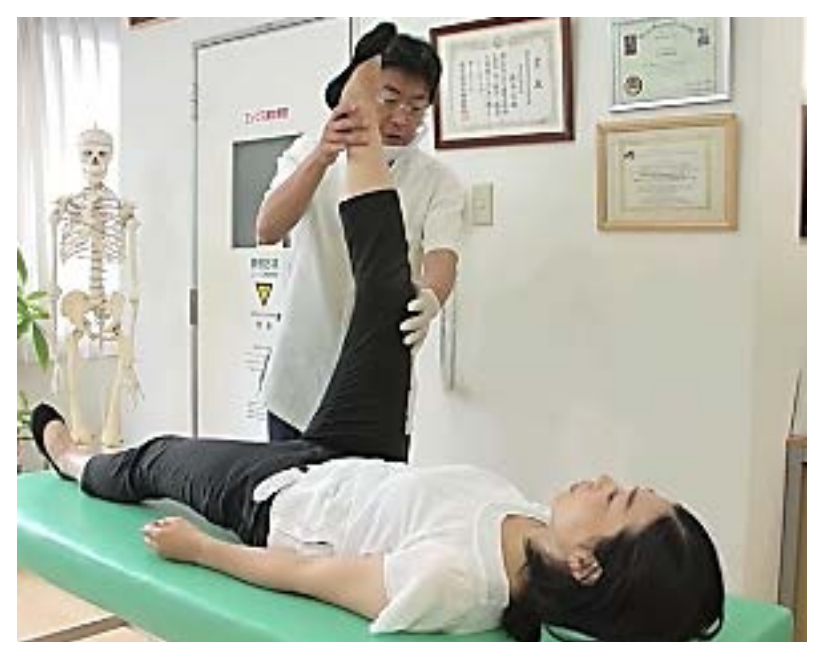

Figure 13. The subject did not feel any tension or pain when a right leg SLR (Straight Leg Raising) test was performed after the treatment. The subject's right leg was able to be lifted up to an angle of approximately 90 degrees.

with balance dysregulation while opening of the mouth results in stretching and pulling of the mucous membrane inwards. The mucous membrane may have been stimulated by the buccal surface. This may also explain the occurrence of the same symptoms when pressure was applied to the subject's cheek. Balance dysregulation due to the stimulation of the buccal mucosa may have been the cause of lumbago in Case 2. The O-ring was easily opened in almost all cases including present two cases when balance dysregulation occurred. However, the mechanism by which this occurs is still unclear. The author thinks that there may be areas like "reflective areas" of reflexology [14]. The harmful stimulation of these areas in the mucous membrane may affect the brain, resulting in this phenomenon. In several patients, the cause of lumbago is unknown. This study provides evidence that dental issues may be one of the causes of this condition that can be treated effectively. Academic cooperation between the dental and medical fields will aid in a better understanding of this phenomenon. Further evidence is required to spread out this treatment widely.

\section{Conclusion}

This study presented two cases of women suffering from lumbago caused by unknown causes. They were cured by a simple dental treatment involving smoothening of rough surfaces of the molars, which were thought to be stimulating the buccal mucosa on the affected side. The results from this study indicated that there might be a close relationship between the tooth and the systemic condition. Even if the symptoms were outside and away from the oral affected area, there was a possibility that dental treatment could play an important role in alleviating the condition. Thus, the cooperation between dental and medical fields might be vital for the understanding and treating such cases.

\section{References}

[1] Watanabe, E.K., Yatani, H., Kuboki, T., Matsuka, Y., Terada, S., Orsini, M.G. and Yamashita, A. (1998) The Relationship between Signs and Symptoms of Temporomandibular Disorders and Bilateral Occlusal Contact Patterns during Lateral Excursions. Journal of Oral Rehabilitation, 25, 409-415. http://dx.doi.org/10.1046/j.1365-2842.1998.00262.x

[2] Karppinen, K., Eklund, S., Suoninen, E., Eskelin, M. and Kirveskari, P. (1999) Adjustment of Dental Occlusion in Treatment of Chronic Cervicobrachial Pain and Headache. Journal of Oral Rehabilitation, 26, 715-721. http://dx.doi.org/10.1046/j.1365-2842.1999.00448.x

[3] Sakaguchi, K., Mehta, N.R., Abdallah, E.F., Forgione, A.G., Hirayama, H., Kawasaki, T. and Yokoyama, A. (2007) Examination of the Relationship between Mandibular Position and Body Posture. Cranio, 25, 237-249.

[4] Gangloff, P., Louis, J.-P. and Perrin, P.P. (2000) Dental Occlusion Modifies Gaze and Posture Stabilization in Human 
Subjects. Neuroscience Letters, 293, 203-206. http://dx.doi.org/10.1016/S0304-3940(00)01528-7

[5] Fujii, Y. (2012) Do Dental Implants Cause Scoliosis? Case Report. Personalized Medicine Universe, 1, 79-80. http://dx.doi.org/10.1016/j.pmu.2012.05.012

[6] Fujii, Y. (2014) Gold Alloy Dental Inlay for Preventing Involuntary Body Movements Caused by Electromagnetic Waves Emitted by a Cell Phone. Open Journal of Antennas and Propagation, 2, 37-43. http://dx.doi.org/10.4236/ojapr.2014.24005

[7] Fujii, Y. (2014) Sense of Balance Disorder Caused by Electromagnetic Waves Collected by a Dental Implant. Acupuncture and Electro-Therapeutics Research, 39, 379.

[8] Fujii, Y. (2014) Sensation of Balance Dysregulation Caused/Aggravated by a Collection of Electromagnetic Waves in a Dental Implant. Open Journal of Antennas and Propagation, 2, 29-35. http://dx.doi.org/10.4236/ojapr.2014.23004

[9] Fujii, Y. (2007) The Dental Treatment That Used Environment of Electromagnetic Wave. Acupuncture and Electro-Therapeutics Research, 32, 291.

[10] Fujii, Y. (2009) The Consideration of the Electromagnetic Wave in Dental Material Substitution. Acupuncture and Electro-Therapeutics Research, 34, 89.

[11] Fujii, Y. (2015) Dental Treatment for Dizziness and Joint Mobility Disorder Caused by Harmful Electromagnetic Waves. Open Journal of Antennas and Propagation, 3, 1-7. http://dx.doi.org/10.4236/ojapr.2015.31001

[12] Yoshiaki, O. (1993) Bi-Digital O-Ring Test for Imaging and Diagnosis of Internal Organs of a Patient. US Patent No. 5188107. http://academic.reed.edu/economics/parker/f11/354/pat/o-ring.pdf

[13] http://bdort.org/

[14] Eizabeth, B.L. (2006) Foot Reflexology. Holistic Nursing Practice, 20, 257-259. http://dx.doi.org/10.1097/00004650-200609000-00009 